\title{
Autophagy promotes the survival and development of tumors by participating in the formation of vasculogenic mimicry
}

\author{
YUN-PENG DING* ${ }^{*}$ XIAO-DONG YANG*, YONG WU and CHUN-GEN XING \\ Department of Gastrointestinal Surgery, The Second Affiliated Hospital of \\ Suzhou University, Suzhou, Jiangsu 225000, P.R. China
}

Received December 31, 2013; Accepted March 4, 2014

DOI: 10.3892/or.2014.3087

\begin{abstract}
Autophagy, type II nonapoptotic cell death, is characterized by the formation of double-membrane cytosolic vesicles, the recycling of damaged cytoplasmic content and the maintenance of genetic stability and cellular homeostasis, under conditions of nutrient starvation, hypoxia or other therapeutic stress. In the present study, we comprehensively discuss its indispensable role in the formation of vasculogenic mimicry (VM), capillary-like tubes consisting of cells from the tumor itself instead of vascular endothelial cells. A short hairpin RNA (shRNA) to silence beclin1, an autophagy-specific gene, was designed, synthesized and subcloned into a vector to establish an autophagy-inhibited group, while negative control and blank groups were also established using human gastric cancer SGC7901 cells. We then investigated the VM formation ability of these three groups and detected changes in gene expression, survival and invasion correspondingly. The results showed that, following the formation of VM, the expression of pluripotent genes (c-myc, oct3/4, sox-2) and autophagyspecific genes (beclin1, ATG5, ATG7) were increased, which was consistent with the negative control cell group. However, the autophagy inhibited cell group did not form VM, and the expression of pluripotent genes was decreased. Moreover, the inhibition of autophagy reduced the survival and invasive ability of cancer cells under stress. We suggest that during the formation of VM, the stable expression of genes and the maintenance of survival and invasion are indispensable. Under a stress environment, autophagy is activated to maintain the
\end{abstract}

Correspondence to: Dr Chun-Gen Xing, Department of Gastrointestinal Surgery, The Second Affiliated Hospital of Suzhou University, Sanxiang 1055, Suzhou, Jiangsu 225000, P.R. China

E-mail: xingcg@126.com

*Contributed equally

Abbreviations: VM, vasculogenic mimicry; 3D, three-dimensional; CSC, cancer stem cell; RT-PCR, reverse transcriptase-polymerase chain reaction; VE-cadherin, vascular endothelial-cadherin; MMP, matrix metalloproteinase

Key words: autophagy, vasculogenic mimicry, three-dimensional culture, pluripotent gene, beclin1 stability of gene expression, maintain survival and invasive ability and facilitate VM formation, which can provide nutrients, oxygen and invasive channels to tumors, facilitating survival and development under stress.

\section{Introduction}

Autophagy, an evolutionarily conserved cell death process, plays a critical role in maintaining energy homeostasis, protein and organelle recycling by transferring defective cytoplasm and organelles into double-membraned vesicles, termed autophagosomes, to degrade and regenerate materials and ATP (1). Autophagy can be activated simultaneously with apoptosis under nutrient starvation, hypoxia or other therapeutic stress (2). However, unlike the latter, autophagy can facilitate genetic stability (3) and cellular homeostasis and play a protective role against stress $(4,5)$. Recent research shows that autophagy is activated as a survival mechanism in cancer under different types of stress $(6,7)$ and helps cancer cells against environment stress and provides a temporary survival pathway by promoting energy regeneration and by maintaining genetic stability and cellular homeostasis. Research has revealed that autophagy guarantees tumor cell survival when apoptosis is inactivated (8). Defective autophagy was found to render mouse mammary epithelial cells susceptible to metabolic stress, prone to DNA damage and genomic instability via gene amplification $(9,10)$. However, another study found that autophagy mainly contributes to tumor suppression. It can mitigate metabolic stress and genome damage to inhibit tumorigenesis. Wang et al found that Akt suppresses autophagy by mTOR-independent phosphorylation of beclin1, ultimately promoting tumorigenesis (11). Whether autophagy plays a tumor-suppressor role or a tumor-promoter role is not clear and needs to be further researched.

Vascularization plays an important role in oxygen and nutrient supplementation, proliferation, invasion and metastasis in tumor tissues. The formation of tumor feeding vessels mainly relies on existing normal endothelial vasculature, which can grow inside tumors and supply oxygen and nutrients. Vasculogenic mimicry (VM) is a new type of tumor angiogenesis model (12). Many highly malignant tumors can simulate vascular channel forming pathways, and differentiate into vascular channels which supply nutrients, oxygen and provide invasive channels to interior tumor tissue (13). Because of the 
independence of the endothelial vascular, vascular endothelial tumor-suppressor drugs are not sensitive to this type of vascularization (14). VM has been found in many highly metastatic malignant tumors $(15,16)$. What is more, its existence is often closely related to the response to various types of tumor treatment and patient prognosis $(17,18)$. Yet, the mechanism of VM is still not clear. A recent study found that autophagy-specific genes beclin 1 and LC3 were both highly expressed in VM-positive melanoma when compared to expression levels in negative samples. The action of autophagy was found to be related to VM and the metastasis of melanoma (19). Therefore, we hypothesized that autophagy contributes to VM formation, which aids cancer cell survival and metastasis. In our research, we aimed to ascertain whether autophagy facilitates VM formation, how it functions and the possible mechanisms finally elucidating the effect of autophagy effect on the promotion of cancer.

\section{Materials and methods}

Cell culture. Human gastric cancer cell line SGC7901 was grown in RPMI-1640 medium supplemented with $10 \%$ fetal bovine serum (FBS) (both from HyClone, Logan, UT, USA), $100 \mathrm{U} / \mathrm{ml}$ penicillin and $100 \mathrm{~g} / \mathrm{ml}$ streptomycin (both from Beyotime Institute of Biotechnology, China). Cells were maintained at $37^{\circ} \mathrm{C}$ in a humidified atmosphere of $5 \% \mathrm{CO}_{2}$.

Short hairpin RNA (shRNA) construction for beclinl knockdown and transfection. shRNA to silence beclin1, an autophagy-specific gene, was designed, synthesized and subcloned into a vector while a negative control was also established. The recombinant vector was then transfected into the SGC7901 cell line and the cells were screened with G418 and assayed using RT-PCR and western blotting.

Tube formation assay. One milliliter of viable cells $\left(2.5 \times 10^{5} /\right.$ $\mathrm{ml}$ ) was added to each well of 24-well plates containing $0.2 \mathrm{ml}$ Matrigel matrix (BD Biosciences, Bedford, MA, USA). Plates were incubated at $37^{\circ} \mathrm{C}$ in $5 \% \mathrm{CO}_{2}$ for $24 \mathrm{~h}$. The vascular mimicry formation ability was evaluated by counting the average length of the vascular mimicry, number and intersecting nods. Each experiment was performed at least three times.

Measurement of cell viability. Cell viability was assessed by the 2-(4,5-dimethyltriazol-2-yl)-2,5-diphenyl tetrazolium bromide (MTT; Amresco Inc., Solon, OH, USA) colorimetric assay. Briefly, $20 \mu \mathrm{l}$ of MTT $(5 \mathrm{mg} / \mathrm{ml})$ was added to each well. After a 4 -h incubation at $37^{\circ} \mathrm{C}$, the cell supernatants were discarded, MTT crystals were dissolved with DMSO and the absorbance was measured at $450 \mathrm{~nm}$. All experiments were conducted with 4-6 wells per experiment and repeated at least 3 times.

Cellular immunofluorescence staining. Cells were fixed in $4 \%$ paraformaldehyde for $10 \mathrm{~min}$ at room temperature with permeation using $0.1 \%$ Triton X-100. Slides were washed three times with phosphate-buffered saline (PBS), blocked with $5 \%$ bovine serum albumin in PBS for $1 \mathrm{~h}$ at $37^{\circ} \mathrm{C}$, incubated with antibodies against LC-3 (1:400; Beyotime) overnight at $4^{\circ} \mathrm{C}$ and with PE-Cy3 secondary antibodies (1:500; Beyotime) for
Table I. Primer sequences.

\begin{tabular}{|c|c|}
\hline Gene & Primer sequences \\
\hline Notch-1 & $\begin{array}{l}\text { 5'-GCAGTTGTGCTCCTGAAGAA } \\
\text { 3'-CGGGCGGCCAGAAAC }\end{array}$ \\
\hline Notch-2 & $\begin{array}{l}\text { 5'-ACTTCCTGCCAAGCATTCC } \\
\text { 3'-GTCCATGTCTTCAGTGAGAAC }\end{array}$ \\
\hline Notch-3 & $\begin{array}{l}\text { 5'-TGACCGTACTGGCGAGACT } \\
\text { 3'-CCGCTTGGCTGCATCAG }\end{array}$ \\
\hline c-Myc & $\begin{array}{l}\text { 5'-CTTCTCTCCGTCCTCGGATTCT } \\
\text { 3'-GAAGGTGATCCAGACTCTGACCTT }\end{array}$ \\
\hline Oct-3/4 & $\begin{array}{l}\text { 5'-GGAGATATGCAAAGCAGAAACC } \\
\text { 3'-CTCAAAATCCTCTCGTTGTGC }\end{array}$ \\
\hline Sox-2 & $\begin{array}{l}\text { 5'-CGGCAACCAGAAAAACAGC } \\
\text { 3'-TCTCCGTCTCCGACAAAAGT }\end{array}$ \\
\hline Beclin-1 & $\begin{array}{l}\text { 5'-AGGTTGAGAAAGGCGAGACAC } \\
\text { 3'-ATGGGTTTTGATGGAATAGGAG }\end{array}$ \\
\hline ATG5 & $\begin{array}{l}\text { 5'-CTCRGCCTTGGAACATCACA } \\
\text { 3'-AGGGTATGCAGCTGTCCATC }\end{array}$ \\
\hline ATG7 & $\begin{array}{l}\text { 5'-CAAAGCCTCCAAAATTCAGC } \\
\text { 3'-GAAGCAGAAAGGCAGCATA }\end{array}$ \\
\hline MMP-2 & $\begin{array}{l}\text { 5'-TGATCTTGACCAGAATACCATCGA } \\
\text { 3'-GGCTTGCGAGGGAAGAAGTT }\end{array}$ \\
\hline MMP-9 & $\begin{array}{l}\text { 5'-CCTGGAGACCTGAGAACCAATC } \\
\text { 3'-CCACCCGAGTGTAACCATAGC }\end{array}$ \\
\hline E-cadherin & $\begin{array}{l}\text { 5'-СААСТTCСССТTCТTCACCC } \\
\text { 3'-ТCCAATGCTATGCCTAGCCG }\end{array}$ \\
\hline
\end{tabular}

$1 \mathrm{~h}$ at room temperature. The slides were observed using a fluorescence microscope.

Real-time quantitative-polymerase chain reaction (PCR). Total-RNA was extracted with the use of TRIzol reagent according to the manufacturer's instructions (Invitrogen, Carlsbad, CA, USA). cDNA was generated by reverse transcription using First Strand cDNA Synthesis kit (Thermo Scientific, Waltham, MA, USA) and oligo(dT) primers in $20 \mu \mathrm{l}$ reaction volume containing $5 \mu \mathrm{g}$ of total RNA pretreated with RNase-free DNase I. PCR was performed with $25 \mu$ l reactions containing $0.5 \mu \mathrm{l}$ diluted cDNA, Taq DNA polymerase, and the primers are listed in Table I. The PCR consisted of an initial denaturation at $94^{\circ} \mathrm{C}$ for $4 \mathrm{~min}$, followed by $25-35$ cycles of $94^{\circ} \mathrm{C}$ for $30 \mathrm{sec}, 58-68^{\circ} \mathrm{C}$ for $30 \mathrm{sec}$ and $72^{\circ} \mathrm{C}$ for $1 \mathrm{~min}$. PCR products were analyzed on $1.5 \%$ agarose gels.

Western blotting. The whole-cell lysates were resolved by sodium dodecyl sulfate polyacrylamide gel electrophoresis (SDS-PAGE) and transferred onto polyvinylidene difluoride (PVDF) membranes (Millipore, Billerica, MA, USA). Blots were blocked and incubated with the anti-beclin1 $(1: 1,000)$, anti-ATG5 $(1: 1,000)$, anti-ATG7 $(1: 1,000)$ (all from Cell Signaling Technology Inc.), anti-c-myc (1:1,000), anti-notch-1 $(1: 1,000)$ (both from Abcam, Cambridge, MA, USA), followed by incubation with a secondary antibody (1:2,000; Santa Cruz Biotechnology, Santa Cruz, CA, USA). Blots were visualized 

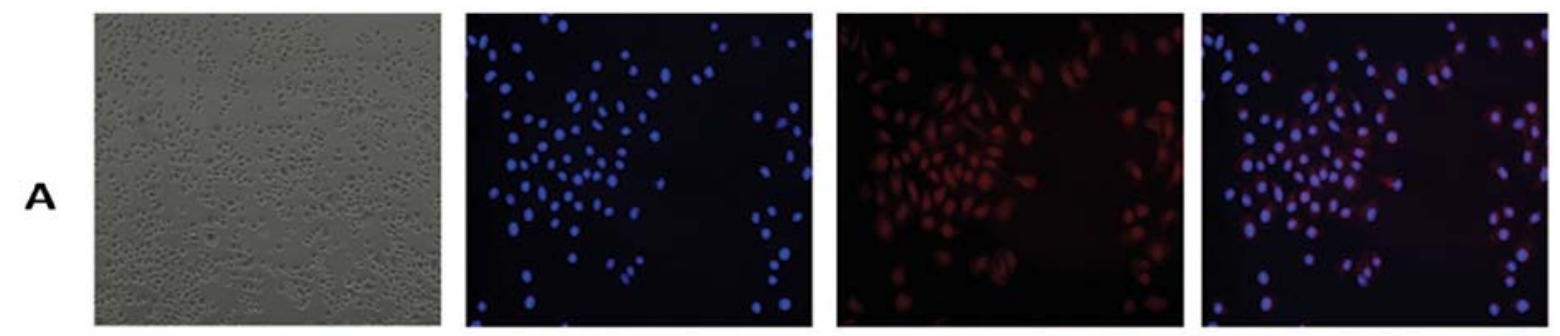

B

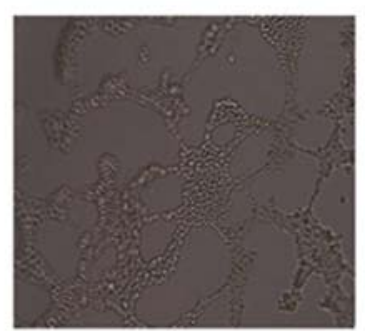

After 2D/3D culture

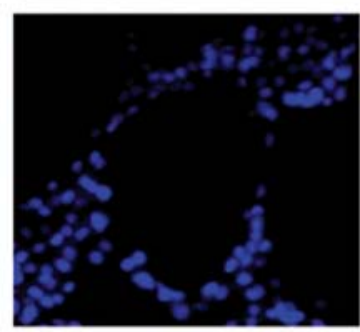

DAPI

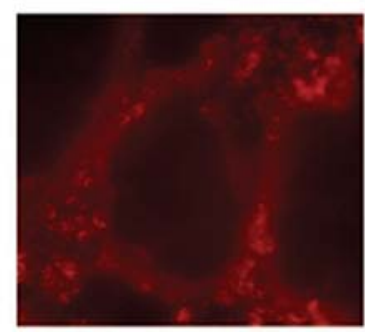

LC-3

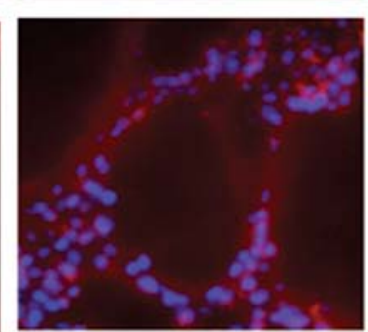

Merge

Figure 1. Autophagy is activated during vasculogenic mimicry (VM) formation in SGC7901 cells. (A) A 24-h 2D culture did not change the morphology of SGC7901 cells. No tubular-like structure was found. (B) After a 24-h 3D culture in Matrigel, the gastric cancer cells formed tubular-like VM structure. The cells were then fixed, sectioned and stained with LC-3 and DAPI. LC-3, an autophagy-specific gene, was overexpressed during VM formation after 3D culture.

using enhanced chemiluminescence detection reagents and exposed to X-ray film. The blots were stripped and re-probed with the anti- $\beta$-actin antibody.

Matrigel invasion assay. The Transwell chamber was used (8-mm, 24-well format; Corning, Costar, NY, USA). In the invasion assay, the insert membranes were coated with diluted Matrigel (BD Biosciences). Cells $\left(1 \times 10^{5}\right)$ were added to the upper chamber and cultured for $24 \mathrm{~h}$. Finally, the insert membranes were cut and stained with crystal violet $(0.04 \%$ in water; $100 \mathrm{ml}$; Beyotime) and the number of invasion cells were counted under an inverted microscope and photographed. Meanwhile, at least three independent experiments were performed for all conditions. The data are shown as means $\pm \mathrm{SD}$.

Statistical analysis. Data are shown as means \pm SD. The statistical difference between the two groups was examined by the Student's t-test. Multiple comparisons were performed by one-way analysis of variance. $\mathrm{P}<0.05$ was considered to indicate a statistically significant result.

\section{Results}

VM formation by SGC7901 cells in 3D culture. Threedimensional (3D) culture mimicks the features of the in vivo environment, allowing cancer cells to live in a matrix or other hydrogel and is superior to two-dimensional (2D) culture in plastic flasks. Because of the absence of complex vascular systems which perfuse oxygenation and nutrition, 3D cultures provide similar hypoxia and a low nutrition stress environment in vivo for cancer cells $(20,21)$.

In the present study, we used Matrigel to establish a 3D culture, and mimick hypoxia and low nutrition in an in vivo stress environment. Gastric cancer SGC7901 cells were grow in the Marigel matrix. After a 24-h 3D culture, a tubular-like

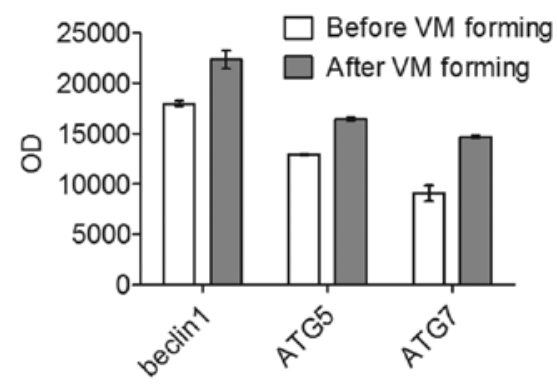

Figure 2. RT-PCR and western blotting were used to detected the expression of autophagy-specific genes (beclin1, ATG5, ATG7) in vasculogenic mimicry (VM) formation. We found that autophagy-specific genes (beclin1, ATG5, ATG7) were increased after VM formation in 3D culture.

structure was noted (Fig. 1A), while a 24-h 2D culture did not change the morphology of SGC7901 cells as tubular-like structures were not present (Fig. 1B).

Autophagy is activated in VM formation of SGC7901 cells. To determine whether autophagy functions in VM formation of gastric cancer cells, we examined the expression of autophagy-specific protein (LC-3) by cellular immunofluorescence staining and detected the expression of additional autophagy-specific genes (beclin1, ATG5, ATG7) by RT-PCR and western blotting in the gastric cancer SGC7901 VM formation process. Cells $\left(2.5 \times 10^{5}\right)$ were plated on a $3 \mathrm{D}$ gel and after a 24-h 3D culture, the formation of VM was observed. Immunofluorescence analysis showed that the expression of autophagy-specific gene LC3 in the SGC7901 cells was increased during VM formation after 3D culture (Fig. 1). PCR and western blotting both showed that the autophagy-specific genes (beclin1, ATG5, ATG7), accompanied by the formation of VM, were highly expressed after VM formation in $3 \mathrm{D}$ culture. (Fig. 2). 


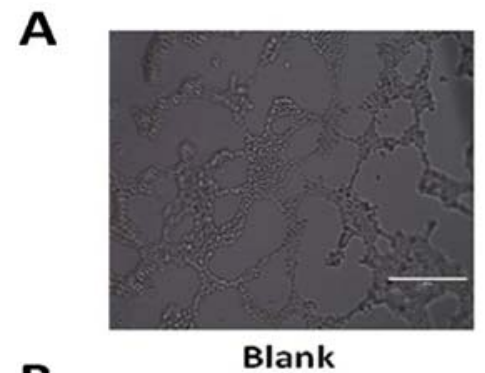

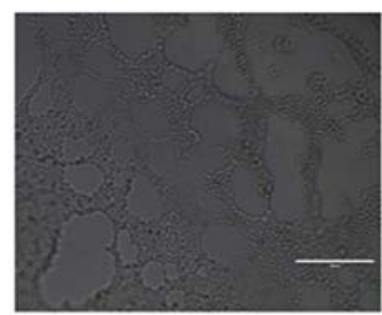

Negative controls

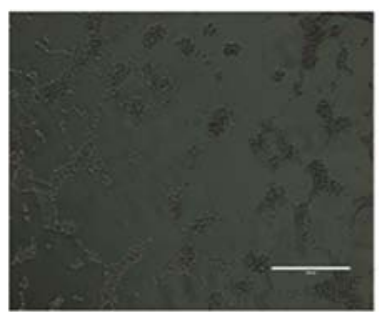

Autophagy inhibited
B

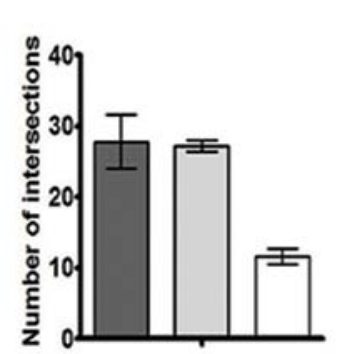

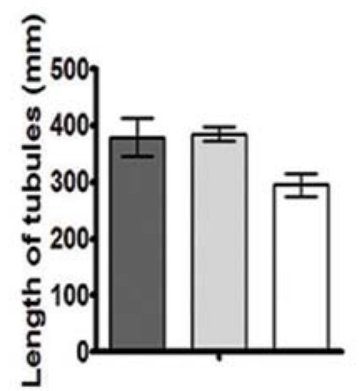

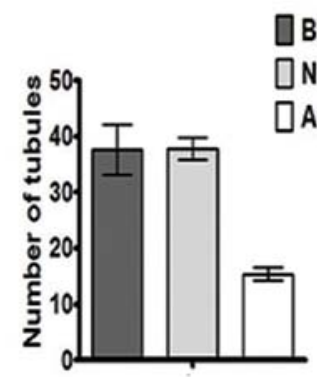

Blank group

$\square$ Negative control group

$\checkmark$ Autophagy inhibited group

Figure 3. Suppression of autophagy-specific gene beclin1 by shRNA in gastric cancer cells suppresses the formation of vasculogenic mimicry (VM). We plated $2.5 \times 10^{5}$ SGC7901 cells of the blank group, negative control group and autophagy inhibited group on 3D gel for a 24-h culture. (A) The formation of VM was observed. Poorly formed tubular structure was observed in the autophagy inhibited group, compared with the others. (B) Histograms represent the number of tubules (right, $\mathrm{P}<0.001$ ), tubular length (middle, $\mathrm{P}<0.001$ ) and the number of intersecting nods (left, $\mathrm{P}<0.001)$ among the different groups. The data represent the means $\pm \mathrm{SD}$ of three independent experiments.

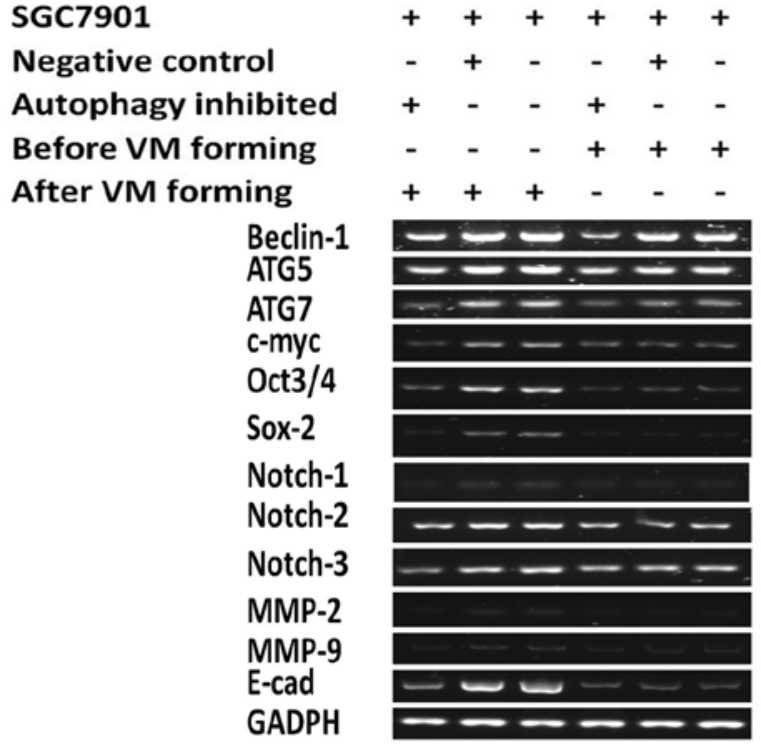

Figure 4. Expression of genes following vasculogenic mimicry (VM) formation. RT-PCR was used to detect the expression of autophagy-specific genes (beclin1, ATG5, ATG7), pluripotency genes (c-myc, oct3/4, sox-2, notch1-3) and other important VM forming genes (MMP-2, MMP-9, E-cad) in the SGC7901 blank group, negative control group, and autophagy inhibited group, before and after 3D culture, respectively. Accompanied by the increased expression of autophagy-specific genes (beclin1, ATG5, ATG7), pluripotency genes (c-myc, oct3/4, sox-2, notch1-3) and other VM forming genes were also increased while a decrease in expression was noted in the beclin1 inhibited group after VM formation.

Inhibition of autophagy-specific gene beclinl in gastric cancer cells suppresses VM. To explore the function of autophagy in the ability of gastric cancer cells to form VM, an shRNA to silence beclin1, an autophagy-specific gene, was designed,

\section{SGC7901 \\ Negative control Autophagy inhibited Before VM forming After VM forming}

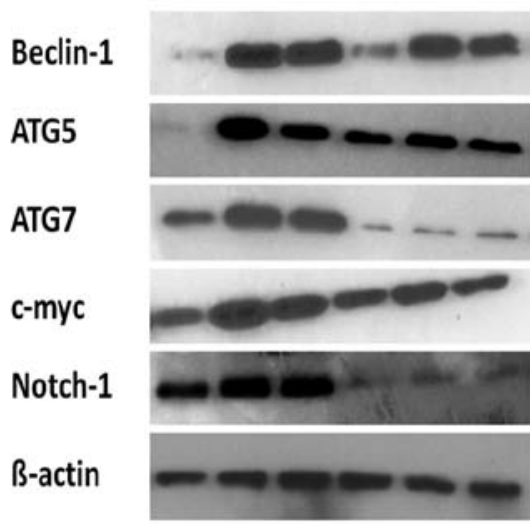

Figure 5. Expression of protein in vasculogenic mimicry (VM) formation Western blotting was used to detected the expression in the SGC7901 blank group, the negative control group, and the autophagy inhibited group, before and after 3D culture, respectively. Following VM formation in the 3D culture, the expression of proteins (c-myc, notch-1) was increased in the negative control group, and the blank group, but decreased markedly following VM formation when the autophagy-specific gene beclin1 was inhibited.

synthesized and subcloned into a vector, while a negative control was also established. Then, the recombinant vector was transfected into the SGC7901 cell line, and the cells were screened with G418 and assayed using RT-PCR and western blotting. Next we plated $2.5 \times 10^{5}$ cells of the autophagy-inhibited group, negative control group and the blank control group on 3D gel, for a 24-h culture. The formation of VM occured 


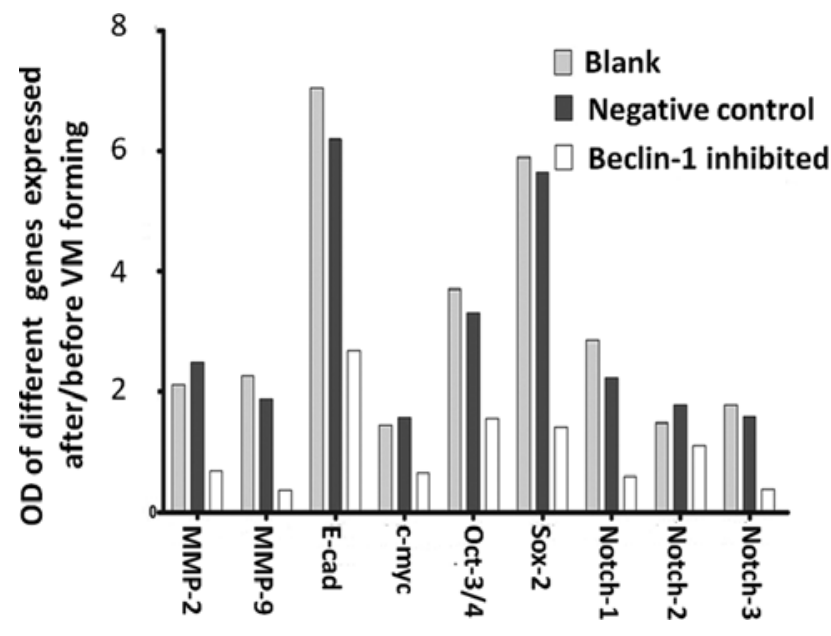

Figure 6. Inhibition of autophagy-specific gene beclin1 alters the stable expression levels of genes during the formation of vasculogenic mimicry (VM). We detected RNA levels of autophagy-specific genes (beclin1, ATG5, ATG7), pluripotency genes (c-myc, oct3/4, sox-2, notch1-3) and other VM forming genes (MMP-2, MMP-9, E-cad) and used the OD ratio of the RNA after/before VM forming to identify the genes involved in the VM formation process when autophagy-specific gene beclin1 was suppressed. The bar chart indicates that the expression of the above genes which are indispensable for VM formation was reduced when autophagy-specific gene beclin1 was inhibited.

in the negative control group and the blank group while the inhibition of autophagy suppressed VM formation as shown by tubular length, number and tubular intersecting nods, compared with the other groups (Fig. 3).

Inhibition of autophagy-specific gene beclinl alters the stable expression of genes in the forming of VM. The above results showed that autophagy suppresses VM. Yet, it remains unclear as to why autophagy is indispensable for VM formation. Thus, we detected changes in the expression of genes between the autophagy inhibited group and the negative control and blank group before and after VM formation in $3 \mathrm{D}$ culture. We, respectively, detected the expression of pluripotency genes (c-myc, oct3/4, sox-2, notch1-3) and other important genes (MMP-2, MMP-9, E-cad) before and after VM formation in 3D culture. PCR and western blotting showed that during VM formation in $3 \mathrm{D}$ culture, expression levels of all of the genes increased in the negative control and the blank groups (Figs. 4 and 5), but these expresson levels were markedly decreased following VM formation when the autophagy-specific gene beclin1 was inhibited (Fig. 6).

Change in survival, proliferation and invasion in beclinlsuppressed cells. We explored the survival and proliferative ability by MTT, and assessed the invasive ability by Transwell test.

RPMI-1640 medium with and without serum was used to mimick the normal and low nutrition stress environments. We plated cells from the negative control group, the blank group and the autophagy inhibited group in RPMI-1640 medium with and without serum. Results showed that the level of proliferation in the three cell groups was similar in the culture with serum. However, the autophagy inhibited group proliferated much more slowly than the other two groups in the culture without serum (Fig. 7).

We detected the invasive ability of the cells by Transwell assay. The migrated cell numbers were significantly reduced in the autophagy inhibited group, when compared with the negative control group and the blank group (Fig. 8).

\section{Discussion}

Autophagy is considered to be a tumor-promoting process which helps cancer cells sustain life by recycling aged or damaged organelles and proteins, regenerating ATP and organelle material in the presence of stress environmental conditions such as nutrient shortage or hypoxia. However, various studies suggest that autophagy mainly contributes to tumor suppression during the early stage of tumorigenesis
A

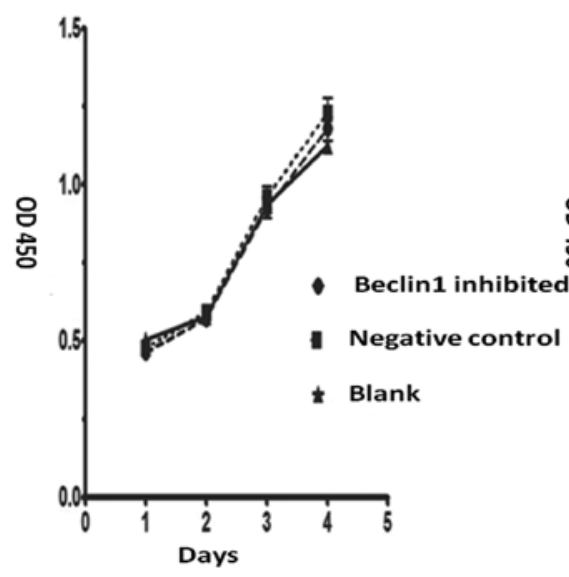

B

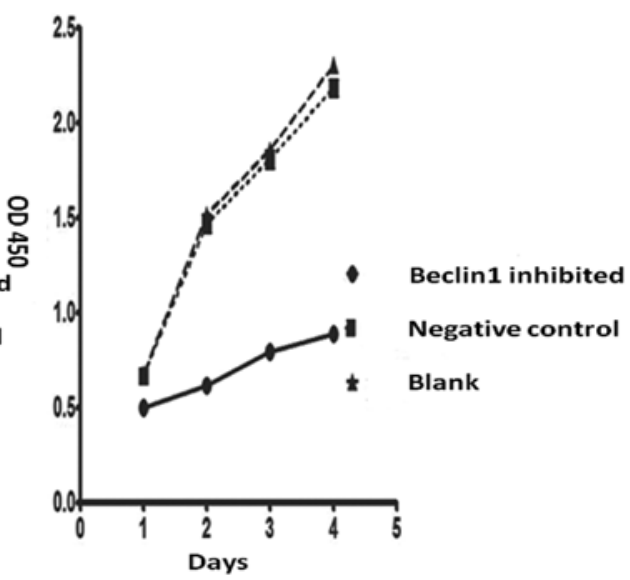

Figure 7. Change in survival and proliferative ability following suppression of beclin. In the MTT assay, RPMI-1640 medium was used with and without serum to mimick a normal and low nutrition environment, respectively. (A) The proliferative ability of the SGC7901 blank group, negative control group and autophagy inhibited group was similar following culture with FBS. (B) However, the cell proliferative ability was suppressed significantly in the autophagy inhibited group in the culture without FBS, when compared with other groups. 


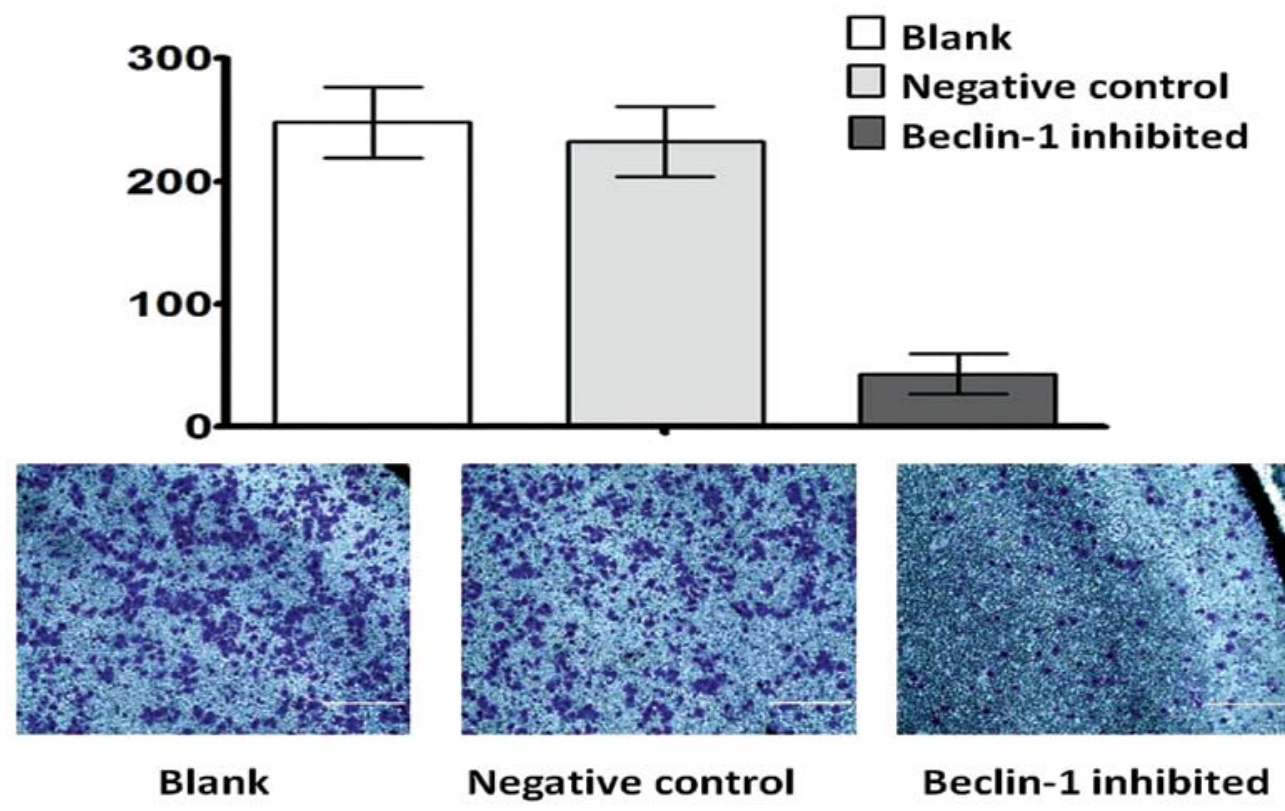

Figure 8. Alteration in the invasive ability of beclin1-silenced cells in Transwell assays. The migrated cell numbers (top) were significantly reduced in autophagy inhibited group $(77.33 \pm 4.25)$ compared with the negative control $(206.66 \pm 8.5, \mathrm{P}<0.001)$ and SGC7901 blank group $(206.66 \pm 8.5, \mathrm{P}<0.001)$.

and deficiency of autophagy leads to genetic instability and tumorigenesis (22).

In the present study, we found that autophagy participates in the formation of VM, vascular-like structures differentiated by cancer cells, which supply nutrients and oxygen and provide invasive channels to the tumor tissue. In a 3D culture, following the formation of the tubular like VM structures by gastric SGC7901 cells, RT-PCR and western blotting revealed that the expression of autophagy-specific genes (beclin1, ATG5, ATG7) was markedly increased.

To further explore the indispensable role of autophagy in the formation of VM, we established an autophagy inhibited group, negative control group and blank group. After a 24-h 3D culture, only the autophagy inhibited group did not form VM. Thus, we confirmed that autophagy not only participates in VM formation but plays an indispensable role in VM formation. In a hypoxic and low nutrition environment, autophagy is activated to facilitate $\mathrm{VM}$ formation to supply nutrients and oxygen and provide invasive channels for cancer cells, promting cancer cell survival and metastasis.

We found that the autophagy inhibited cell group in the 3D culture did not form VM, and numerous dying or dead cell were observed. Thus, we used the MTT assay to test the survival ability of SGC7901 cells in a low nutrition environment when autophagy was inhibited. The result showed that the survival ability of the autophagy inhibited cell group, negative control group, and blank group was not altered in the full nutrition environment, but in the low nutrition environment, the survival ability of the autophagy inhibited cell group was reduced when compared with the other two cell lines in culture without nutrition. Thus, we confirmed that autophagy guarantees the survival of SGC7901 cancer cells in an adverse environment, promotes cancer cell survival and then promotes the formation of VM in an adverse environment.

Recent research revealed that the formation of VM relies on the pluripotent ability of a few cancer cells in tumor tissues, which are called cancer stem cells (CSCs). It is believed that cancer stem cells, similarly to normal embryonic stem cells, have the capacity of self-renewal and differentiation that is responsible for the heterogeneity in cancer (23-26). Under the control of same pluripotency genes, these pluripotency cells can differentiate into cells with different capacities, so they can undergo and adapt to different stress. Previous research found that when cells were transfected with transcription factors such as c-myc, oct 4, sox 2 into human and mouse somatic cells, the cells could become pluripotent stem cells and had directional differentiation features (27-29), which help them survive under a stress environment.

In the present study, we found increased expression of the pluripotency control genes (c-myc, oct-4, sox-2, notch1-3) following VM formation in 3D culture, which suggests that, under 3D culture in vitro, with the management of some pluripotency control genes, CSCs have the capacity of vascular endothelial cells and form VM to overcome environmental stress. However, the expression of genes which were increased in the negative control group and the blank group, were markedly decreased in the autophagy inhibited cell group. We believe that stem cells protect their genome from damage to maintain their pool and self-renewal capacity and during the tumorization of cells, autophagy protects genomic stability by retarding damage/repair cycle, and protecting cell homeostasis. Various studies found the significant role of autophagy in pluripotent stem (iPS) cell generation and differentiation processes $(30,31)$. Thus, we can confirm that autophagy contributes to the stable expression of pluripotency genes which are indispensable to VM formation. When autophagy is inhibited, cancer cells are unable to manage pluripotency gene expression in hypoxia, low nutrition or other adverse environments. Finally, VM cannot form which was observed in our study.

VE-cadherin, MMP-2 and MMP-9 are invasion and migration molecules of cancer cells, and have been identified as important players in melanoma VM. In the absence 
of VE-cadherin and MMPs, VM tube formation does not occur (32). Several studies have found that the invasive and migratory abilities of cells are important in vascularization $(33,34)$. In the present study, the expression of VE-cadherin, MMP-2, and MMP-9 was increased after VM formation in 3D culture, but when autophagy was inhibited expression of these genes was decreased, and Transwell assay showed that the invasion of the autophagy inhibited cell group was also markdly decreased when compared with the negative control group and blank group. This indicates that autophagy can facilitate the invasive and migratory abilities of cancer cells by ensuring the stability of expression of VE-cadherin, MMP-2, and MMP-9, contributing to the formation of VM in 3D culture.

In conclusion, our data, for the first time, indicate that autophagy participates in VM formation, and inhibition of autophagy suppresses VM formation and the relevant mechanisms. In a stress environment, autophagy, by maintaining the survival of cancer cells, ensures the stable expression of pluripotency control genes, managing the invasive and migratory abilities of cancer cells, and promotes VM formation which supplies nutrients, oxygen and provide invasive channels to the interior tumor tissue. In this manner, autophagy promotes the survival and development of tumors.

\section{Acknowledgements}

This study was supported by the National Natural Science Foundation of China (no. 81172348) and Science Foundation of Suzhou (no. SYSD2013090, no. SS0834).

\section{References}

1. Singh R and Cuervo AM: Autophagy in the cellular energetic balance. Cell Metab 13: 495-504, 2011.

2. Bursch W: The autophagosomal-lysosomal compartment in programmed cell death. Cell Death Differ 8: 569-581, 2001.

3. Karantza-Wadsworth V, Patel S, Kravchuk O, Chen G, Mathew R, Jin S and White E: Autophagy mitigates metabolic stress and genome damage in mammary tumorigenesis. Genes Dev 21: $1621-1635,2007$.

4. Meléndez A, Tallóczy Z, Seaman M, Eskelinen EL, Hall DH and Levine B: Autophagy genes are essential for dauer development and life-span extension in C. elegans. Science 301: 1387-1391, 2003.

5. Bergamini E, Cavallini G, Donati A and Gori Z: The role of macroautophagy in the ageing process, anti-ageing intervention and age-associated diseases. Int J Biochem Cell Biol 36 : 2392-2404, 2004

6. Bartolome A, Guillen C and Benito M: Autophagy plays a protective role in endoplasmic reticulum stress-mediated pancreatic $\beta$ cell death. Autophagy 8: 1757-1768, 2012.

7. Degenhardt K, Mathew R, Beaudoin B, Bray K, Anderson D, Chen G, Mukherjee C, Shi Y, Gélinas C, Fan Y, Nelson DA, Jin $S$ and White E: Autophagy promotes tumor cell survival and restricts necrosis, inflammation, and tumorigenesis. Cancer Cell 10: 51-64, 2006.

8. Degenhardt K and White E: A mouse model system to genetically dissect the molecular mechanisms regulating tumorigenesis. Clin Cancer Res 12: 5298-5304, 2006.

9. Burstein HJ: The distinctive nature of HER2-positive breast cancers. N Engl J Med 353: 1652-1654, 2005.

10. Chin K, DeVries S, Fridlyand J, Spellman PT, Roydasgupta R, Kuo WL, Lapuk A, Neve RM, Qian Z, Ryder T, Chen F, Feiler H, Tokuyasu T, Kingsley C, Dairkee S, Meng Z, Chew K, Pinkel D, Jain A, Ljung BM, Esserman L, Albertson DG, Waldman FM and Gray JW: Genomic and transcriptional aberrations linked to breast cancer pathophysiologies. Cancer Cell 10: 529-541, 2006.

11. Wang RC, Wei Y, An Z, Zou Z, Xiao G, Bhagat G, White M, Reichelt $\mathrm{J}$ and Levine B: Akt-mediated regulation of autophagy and tumorigenesis through Beclin 1 phosphorylation. Science 338: 956-959, 2012.
12. Maniotis AJ, Folberg R, Hess A, Seftor EA, Gardner LM, Pe'er J, Trent JM, Meltzer PS and Hendrix MJ: Vascular channel formation by human melanoma cells in vivo and in vitro: vasculogenic mimicry. Am J Pathol 155: 739-752, 1999.

13. Hendrix MJ, Seftor EA, Hess AR and Seftor RE: Molecular plasticity of human melanoma cells. Oncogene 22: 3070-3075, 2003.

14. Guzman G, Cotler SJ, Lin AY, Maniotis AJ and Folberg R: A pilot study of vasculogenic mimicry immunohistochemical expression in hepatocellular carcinoma. Arch Pathol Lab Med 131: 1776-1781, 2007.

15. Folberg R and Maniotis AJ: Vasculogenic mimicry. APMIS 112: 508-525, 2004

16. Sun B, Zhang S, Zhang D, Du J, Guo H, Zhao X, Zhang W and Hao X: Vasculogenic mimicry is associated with high tumor grade, invasion and metastasis, and short survival in patients with hepatocellular carcinoma. Oncol Rep 16: 693-698, 2006.

17. Van der Schaft DW, Seftor RE, Seftor EA, Hess AR, Gruman LM, Kirschmann DA, Yokoyama Y, Griffioen AW and Hendrix MJ: Effects of angiogenesis inhibitors on vascular network formation by human endothelial and melanoma cells. J Natl Cancer Inst 96: 1473-1477, 2004

18. Cai XS, Jia YW, Mei J and Tang RY: Tumor blood vessels formation in osteosarcoma: vasculogenesis mimicry. Chin Med 117: 94-98, 2004.

19. Han C, Sun B, Wang W, Cai W, Lou D, Sun Y and Zhao X: Overexpression of microtubule-associated protein-1 light chain 3 is associated with melanoma metastasis and vasculogenic mimicry. Tohoku J Exp Med 223: 243-251, 2011.

20. Kimlin LC, Casagrande G and Virador VM: In vitro three-dimensional (3D) models in cancer research: an update. Mol Carcinog 52: 167-182, 2013.

21. Yamada KM and Cukierman E: Modeling tissue morphogenesis and cancer in 3D. Cell 130: 601-610, 2007.

22. Sun K, Deng W, Zhang S, Cai N, Jiao S, Song J and Wei L: Paradoxical roles of autophagy in different stages of tumorigenesis: protector for normal or cancer cells. Cell Biosci 3: 35, 2013.

23. Clevers H: The cancer stem cell: premises, promises and challenges. Nat Med 17: 313-319, 2011.

24. Magee JA, Piskounova E and Morrison SJ: Cancer stem cells: impact, heterogeneity, and uncertainty. Cancer Cell 21: 283-296, 2012.

25. Visvader JE and Lindeman GJ: Cancer stem cells: current status and evolving complexities. Cell Stem Cell 10: 717-728, 2012.

26. Vazquez-Martin A, Oliveras-Ferraros C, Del Barco S, Martin-Castillo B and Menendez JA: The anti-diabetic drug metformin suppresses self-renewal and proliferation of trastuzumab-resistant tumor-initiating breast cancer stem cells. Breast Cancer Res Treat 126: 355-364, 2011.

27. Yu J, Vodyanik MA, Smuga-Otto K, Antosiewicz-Bourget J, Frane JL, Tian S, Nie J, Jonsdottir GA, Ruotti V, Stewart R, Slukvin II and Thomson JA: Induced pluripotent stem cell lines derived from human somatic cells. Science 318: 1917-1920, 2007.

28. Lowry WE, Richter L, Yachechko R, Pyle AD, Tchieu J, Sridharan R, Clark AT and Plath K: Generation of human induced pluripotent stem cells from dermal fibroblasts. Proc Natl Acad Sci USA 105: 2883-2888, 2008.

29. Park IH, Zhao R, West JA, Yabuuchi A, Huo H, Ince TA, Lerou PH, Lensch MW and Daley GQ: Reprogramming of human somatic cells to pluripotency with defined factors. Nature 451: 141-146, 2008.

30. Naka K and Hirao A: Maintenance of genomic integrity in hematopoietic stem cells. Int J Hematol 93: 434-439, 2011.

31. Song YJ, Zhang SS, Guo XL, Sun K, Han ZP, Li R, Zhao QD, Deng WJ, Xie XQ, Zhang JW, Wu MC and Wei LX: Autophagy contributes to the survival of $\mathrm{CD} 133^{+}$liver cancer stem cells in the hypoxic and nutrient-deprived tumor microenvironment. Cancer Lett 339: 70-81, 2013.

32. Hendrix MJ, Seftor EA, Meltzer PS, Gardner LM, Hess AR, Kirschmann DA, Schatteman GC and Seftor RE: Expression and functional significance of VE-cadherin in aggressive human melanoma cells: role in vasculogenic mimicry. Proc Natl Acad Sci USA 98: 8018-8023, 2001.

33. Thorns V, Walter GF and Thorns C: Expression of MMP-2, MMP-7, MMP-9, MMP-10 and MMP-11 in human astrocytic and oligodendroglial gliomas. Anticancer Res 23: 3937-3944, 2003.

34. Zygmunt M, Munstedt K and Lang U: The role of vasculo- and angiogenesis in embronic and fetal development. A short review. Gynakologe 34: 812, 2001. 